\title{
The development of e-commerce by web celebrity live webcast with goods
}

\author{
Hui $\mathrm{He}^{1}$ \\ ${ }^{1}$ Electronic Commerce Department of Business School JiangXi Normal University NanChang, China
}

\begin{abstract}
Online celebrities with goods refers to celebrities with the Internet "+" era background and their own unique advantages, through micro blog, wechat, short video and live broadcast platform to promote the sales of goods from the media. The purpose of this paper is to explore the development prospect of ecommerce under the background of live broadcast of online celebrities with goods. This paper discusses the impact of online celebrity live broadcast on e-commerce and the existing problems, and puts forward the corresponding solutions for reference.
\end{abstract}

\section{INTRODUCTION}

In the context of new media convergence technology, web celebrity live streaming has formed a networked relationship of body, consumption and media. Web celebrity live broadcast brings certain value to merchants. Its strong interactivity and more diversified scenes also become important weights to attract e-commerce businesses ${ }^{[1]}$. Web celebrity generate a surge in traffic and orders, and it remains an increase in orders. The main purpose of users entering the studio is to pursue entertainment, not to buy products. If web celebrity wants to drive the audience to buy products, it needs to spend more effort to convince fans of the products themselves, so as to stimulate fans' consumption ${ }^{[2-3]}$. And now the Matthew effect of web celebrity live broadcast is increasingly obvious, the head web celebrity far from ordinary live broadcast; according to web celebrity industry professionals, web celebrity incubators have a very strict internal elimination mechanism, the real money is the head of 8898 the $10-20 \%$ web celebrity group. And there are a lot of stars, the health of the host began to broadcast industry, other social APP to be shared in the relevant tips and skin care for the consumer's consumption ability limited, and the effect of eyeball, ordinary net red people will bring their own fans as the wave of the crowd to join lost quite a number of fans at the same time ${ }^{[4-7]}$.

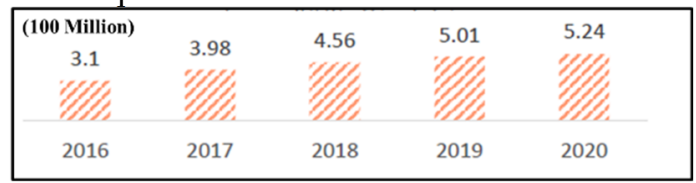

Fig 1. Chinese online live streaming users from 2016 to 2020

As can be seen from Figure 1, the number of users of online live broadcasting has increased sharply in recent years, from 310 million in 2016 to 524 million in 2020. It provides a good foundation for the development of web celebrity economy.

\section{METHODOLOGY AND DISCUSSION}

Web celebrity live broadcasting has created a new ecommerce model and changed the consumption pattern of consumers, which is a new bright color of China's economy. Behind this, the diversified and personalized needs of consumers are constantly explored and a large number of personalized products are poured out. But these are all based on the premise that the number of web celebrity fans is real.At present, with some web celebrity live "car roll", web celebrity live with goods also gradually remove the bubble, return to rationality .Industry analysis believes that, from the perspective of users, the enthusiasm for impulse consumption seems to have begun to decline, users are gradually desensitized to the talk about live broadcast with goods, and it is very likely to have aesthetic fatigue to the head web celebrity ${ }^{[8]}$. Industry analysis believes that, in the era of fan economy, web celebrity with goods is undisputable, but not all goods are suitable for live broadcast, according to the characteristics of anchors, scenes and products, applicable types of goods are more limited. How to view the impact of web celebrity live streaming on the development of e-commerce is mainly reflected in the following aspects:

\subsection{Influence on online market: Live broadcast can bring certain increment to e-commerce}

Although web celebrity with goods emerged a lot of chaos, but the value of live broadcast to businesses cannot be ignored. According to the white paper on the ecological development of web celebrity e-commerce 2019, the purchase conversion rate of traditional e-commerce is only $0.37 \%$, that of social e-commerce is $6 \% \sim 10 \%$, and that of top web celebrity e-commerce can reach $20 \%\left[{ }^{9}\right]$.Compared with the traditional TV shopping 
program, more interactive and more diversified scenes are the important weights for the live broadcast mode to attract e-commerce providers.

For consumers, live streaming is also more novel and interesting. To a large extent, many consumers like and trust web celebrity and want to use the same product with the other party. They usually think that "web celebrity generally introduces hot style products, and consumers will have a psychology of following the fashion. In addition, there will be different levels of discounts and discounts during the broadcast, making things cheaper." According to the 2019 Ecological Development Trend Report of Taobao Live Broadcast released by Taobao.com and Taobao Live Broadcast, in 2018, the annual turnover of Taobao Live broadcast alone exceeded 100 billion yuan, accounting for more than $7 \%$ of the total retail turnover of Taobao. The monthly growth rate of Taobao Live broadcast is up to $350 \%$, and the conversion rate into the store is over $65 \%$. A total of 81 anchors lead the annual sales of Over 100 million yuan, and there are hundreds of anchors with monthly income of millions, creating a new incremental market of 100 billion yuan.

Among them, live broadcasting also shows great advantages in the field of poverty alleviation. The emergence of new jobs such as "county chief anchor" partner selling goods, the first broadcast room of new agricultural products, and "village broadcasting" has driven villagers out of poverty and become rich. For example, Taobao Direct broadcast launched the "village broadcast" poverty alleviation program in 2019, and so far, more than 300 county rural products have received orders from all over the country through broadcast studios. For example, Skinny brother, a host in Hainan, sold more than 300,000 yuan worth of noble wives and man in a live broadcast. Xiangxi younger sister through Taobao live broadcast, two days to sell 400,000 unsalable kiwi; On the first day of its debut in Hunan province, more than 4,200 jins of cherries and 26,000 eggs were sold.

The biggest contribution of video e-commerce (including live streaming with goods) is to present products to consumers in a $360^{\circ}$ all-round way through video. Improving consumers' understanding of products is a benefit brought by live streaming. It is reported that the content of the current broadcast covers the whole process of design, production and manufacturing.

\subsection{Guide web celebrity live broadcasting to bring goods back to rationality}

Web celebrity take goods, its essence also belongs to the category of fan economy. The number and stickiness of fans are also related to liquidity." A lot of web celebrity followers are just being brushed up, or a false boom created by the platform. "Zhang yi, founder and chief analyst of imedia consulting, told reporters that if the number of web celebrity fans is real, it must be worthwhile for merchants to invite each other to live broadcast with goods. It can expand the scope of the products' influence, but don't have too great expectations for the goods. Live broadcast plays more of a publicity role, so there is no guarantee for the goods.
Live-streaming with goods is not a panacea, because the attributes of the platforms are different, and it is difficult to guarantee the liquidity of anchors. The reporter found that at present, the largest category of goods with Taobao live broadcast is clothing, followed by beauty makeup, and then maternal and child, food, jewelry, etc. The popular categories of fast Live streaming are mainly low gross margin and destocking commodities. The popular category on Douyin platform is mainly beauty makeup, each platform's core users have different demands. Not everyone can accept the goods. For example, long video platforms are totally unreasonable, and pure live streaming platforms of shows and games are not suitable for carrying goods excessively.

Industry analysis believes that fans economic era, web celebrity with goods is beyond reproach, but the premise is to choose their familiar, quality guaranteed products. If the product does not check, blindly to consume fans of love and trust, this road is not far away ${ }^{[10]}$.

\subsection{The derivation of web celebrity live webcast goods}

There are many limited types of commodities applicable to e-commerce live broadcast, which are mainly focused on clothing, beauty makeup and other products at the present stage. Second, it costs more to hire stars and Internet celebrities to broadcast. To innovate the form of live broadcasting, expand the categories of electricity products, and innovate the mechanism of anchor selection, we can consider exploring and cultivating the internal staff web celebrity of e-commerce companies, and transfer it from the external introduction to the internal training. For the mode of "live broadcast + e-commerce", it is reasonable for businesses to attach great importance to live broadcast. However, it is necessary to reduce expectations for live broadcast delivery. Not all products are suitable for live broadcast. For consumers, do not blindly believe web celebrity with goods, because the other side does not have the ability to audit, cannot guarantee the quality, but to have a big brand to buy; For anchors or those who want to enter this industry, they should pay attention to the quality of products and the degree of publicity. And don't think of it as a career that can make you rich overnight.

\section{CONCLUSION}

As a new thing, web celebrity live broadcasting has developed rapidly and achieved remarkable results. However, many deficiencies have been exposed in its development process. For example, big Internet celebrities are developing well while small web celebrity can only barely enough to get by. Web celebrity broadcast mode is not perfect, and the development cost is high. A short life cycle of web celebrity and other issues, we should plan a new way for web celebrity live broadcast to make web celebrity live broadcast sustainable development. With the development of web celebrity live broadcast, the strong carrying capacity of web celebrity enables many brand owners to see the possibility of selling goods through web celebrity carrying. Many brand owners begin to cooperate 
with web celebrity and let web celebrity start to promote carrying goods, among which there are newly popular goods: perfect diary, plain man and so on; the new brand achieved brand promotion and sales through the drive of web celebrity, and also had a good effect. But "web celebrity with goods" also appeared a lot of problems: web celebrity entry threshold is very low, some quality is not high network red will have some uncivilized language and behavior in the broadcast room, will mislead consumers through inappropriate description and exaggerated product functions; There are also a lot of uneven products through the promotion of web celebrity profit, to web celebrity live broadcast brought a negative impact. Web celebrity live broadcast makes traffic realize realization, which is a very popular business model now. In the current web celebrity live broadcast development peak period, do not lose conscience, break the law and lose the trust of fans in order to seek temporary abnormal interests. At the same time, as a manufacturer of product production and brand manufacturing, it is more obliged to strictly control the product quality, really make good use of the outlet of network celebrity live, provide high-quality products, and at the same time enhance the brand awareness and reputation, so as to obtain new dividends in this era in the context of new media. Whether live platform or web celebrity personally as well as the behind team need to be taken seriously product recommendations on the highspeed development of web celebrity, not only of the high interest irresponsibly recommended, at the same time in the law also to illegal web celebrity, and manufacturers, suppliers, clients, and accountability for serious network platform.

\section{ACKNOWLEDGMENT}

This research was supported by the Education Department Science Foundation of Jiangxi Province (No. GJJ150370)

\section{REFERENCES}

1. The managerial implications of the learning organization: a newtool for internal marketing $[\mathrm{J}]$. Dennis J. Cahill. Journal of Services Marketing . 1995 (4)

2. Marketing through Spirituality: A Case of Patanjali Yogpeeth[J].Vinod Kumar,Ankit Jain,Zillur Rahman,Akhil Jain. Procedia - Social and Behavioral Sciences . 2014

3. The YouTube Social Network. Mirjam Wattenhofer, Roger Wattenhofer,Zack Zhu. Cybernetics and Systems Analysis . 2012

4. An Interest-Based Per-Community P2P Hierarchical Structure for Short Video Sharing in the YouTube Social Network. Haiying Shen, Yuhua Lin, Chandler,H. Distributed Computing Systems (ICDCS),2014 IEEE 34th International Conference on . 2014

5. Ethics of Celebrities and Their Increasing Influence in 21st Century Society[J] . Chong Ju Choi,Ron Berger. Journal of Business Ethics. 2010 (3)
6. Keeping Up the Kardashian Brand:Celebrity, Materialism,and Sexuality Amanda Scheiner McClain.Lanham:Lexington Books,2014.. Mcdonnell A. Journal of American Culture . 2016

7. Determinants on Mechanism of Emotional Marketing:Emotional Intelligence,Perception of Emotional Labor"Action,Efficacy and Customer"Coping Strategy on Customer Satisfaction. Park H. Dissertations\&Theses-Gradworks . 2013

8. Interactive Marketing. Ehrlich E,Fanelli D. The Financial Services Marketing Handbook:Tactics and Techniques that Produce Results . 2016

9. Are key marketing topics adequately covered in strategic management?. David M E,David F R. Journal of Strategic Marketing . 2016

10. Determinants of intention to use the mobile banking apps: An extension of the classic TAM model[J] . F. Muoz-Leiva,S. Climent-Climent,F. LiébanaCabanillas. Spanish Journal of Marketing - ESIC . 2016 